\title{
Relationship between Occurrence of Birds and Vegetation Structure of Riparian Habitats
}

\author{
Ellepola G. ${ }^{1 *}$ and Rajakaruna S.L. ${ }^{2}$ \\ ${ }^{I}$ Department of Zoology, Faculty of Science, University of Peradeniya, Peradeniya, Sri Lanka \\ ${ }^{2}$ Post Graduate Institute of Science, University of Peradeniya, Peradeniya, Sri Lanka \\ *gajaba3@gmail.com
}

\begin{abstract}
Riparian lands and their vegetation provide important habitat for terrestrial animals including birds. Even though riparian lands may occupy only a small percentage of the catchment landscape they provide nesting and feeding habitats for a large number of bird species. But due to construction of dams, human uses of riparian vegetation, logging, road construction, livestock grazing and sand mining riparian habitats are depleting in Sri Lanka. The present study was aimed to compare habitat use by birds with available riparian vegetation, and to compare bird population characteristics among riparian habitats with different vegetation structure. In order to achieve the objectives, occurrence of birds was studied in two different riparian systems; 'Loggal oya' and 'Minipe' area of Mahaweli River which are having two different vegetation structures. There are significant differences in the abundance of canopy vegetation and understory vegetation and no such difference in abundance of ground vegetation between two sites. $500 \mathrm{~m}$ line transects with a width of $40 \mathrm{~m}$ were placed parallel to the stream flow and birds were recorded. Birds were recorded for 10 minutes at each of 10 equally spaced stations along the transect and while moving between stations. Species and number of birds were recorded. Seventy four bird species were observed with a highest diversity in the Loggal oya $\left(\mathrm{H}^{\prime}=2.58\right.$ with respect to $\mathrm{H}^{\prime}=2.42$ in Minipe). Bird density was also higher in the Loggal oya with a significant difference. Canonical correspondance analysis showed that Canopy cover is the highest contributing factor for the distribution of birds. A positive correaltion was observed between the vegetation structure and the abundance of birds thus, concluding that riparian habitats are imporatant areas for birds for its survival. By understanding the associations between birds and habitat, management activities can be implemented to provide appro-priate habitat for desired species.
\end{abstract}

Keywords: Riparian habitat, Vegetation structure 